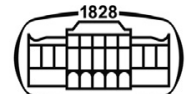

AKADÉMIAI KIADÓ

\title{
An empirical study of affective and cognitive functions in Compulsive Sexual Behavior Disorder
}

\section{Journal of Behavioral Addictions}

10 (2021) 3, 657-674

DOl:

$10.1556 / 2006.2021 .00056$

(c) 2021 The Author(s)

\section{FULL-LENGTH REPORT}

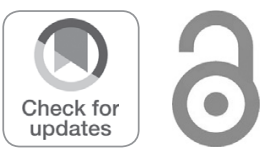

${ }^{*}$ Corresponding author. Tel.: +48 (22) $5831380 / 81$.

E-mail: mdraps@psych.pan.pl

\section{MAEGORZATA DRAPS $^{1 *}{ }^{*}$, GUILLAUME SESCOUSSE ${ }^{2} \odot$, MATEUSZ WILK $^{1}$, KATARZYNA OBARSKA ${ }^{1} \odot$, IZABELA SZUMSKA ${ }^{1} \odot$, WERONIKA ŻUKROWSKA ${ }^{1}$, ALEKSANDRA MAJKOWSKA ${ }^{1}$, EWELINA KOWALEWSKA ${ }^{3} \odot$, JULIA SZYMANOWSKA ${ }^{4}$, URSZULA HAMERSKA ${ }^{4}$, MAGDA TRYBUŚ ${ }^{4}$, KAROLINA GOLEC ${ }^{5}$, IWONA ADAMSKA ${ }^{6}$, KAROL SZYMCZAK ${ }^{7} \odot$ and MATEUSZ GOLA ${ }^{1,8}{ }_{\odot}$}

\footnotetext{
${ }^{1}$ Institute of Psychology, Polish Academy of Sciences, Warsaw, Poland

${ }^{2}$ Lyon Neuroscience Research Center, The National Center for Scientific Research and The National Institute of Health and Medical Research, Lyon, France

${ }^{3}$ Department of Psychiatry, Centre of Postgraduate Medical Education, Warsaw, Poland

${ }^{4}$ SWPS University of Social Sciences and Humanities, Warsaw, Poland

${ }^{5}$ Faculty of Psychology, Warsaw University, Warsaw, Poland

${ }^{6}$ Academy of Special Education, Warsaw, Poland

${ }^{7}$ Institute of Psychology, The Maria Grzegorzewska University, Warsaw, Poland

${ }^{8}$ Swartz Center for Computational Neuroscience, Institute for Neural Computations, University of California San Diego, San Diego, USA
}

Received: March 21, 2021 Revised manuscript received: July 19, 2021; August 5, 2021 - Accepted: August 6, 2021 Published online: September 22, 2021

\begin{abstract}
Background and aims: Despite the inclusion of the Compulsive Sexual Behavior Disorder (CSBD) in the International Classification of Diseases, very little is known about the underlying affective and cognitive processes. To fill this gap, we compared CSBD subjects and Healthy-Controls (HC) across negative/ positive valence, cognitive and sensorimotor systems, as proposed by the Research Domain Criteria framework. Methods: 74 heterosexual CSBD and 66 matched HC males were studied with 10 questionnaires and 8 behavioral tasks. Analyses were conducted with frequent and Bayesian statistics. Results: CSBD individuals showed significantly higher (than HC) punishment sensitivity, anxiety, depression, compulsivity, and impulsivity symptoms. Frequentist statistical analysis revealed significant interaction between subject group and condition in Incentive Delay Task, concerning the strength of motivation and hedonic value of erotic rewards. Bayesian analysis produced evidence for the absence of group differences in Facial Discrimination Task, Risk-Ambiguity Task, and Learning Task. Also, Bayesian methods provided evidence for group differences in the Emotional Stroop Task and the Incentive Delay Task. Sexual Discounting Task, Attentional Network Task, and Stop Signal Task produced mixed results. Conclusions: Higher punishment sensitivity and impulsivity among CSBD subjects, along with significant interaction between these groups and erotic vs. non-erotic reward processing is in line with previous findings on negative/positive valence alterations in CSBD patients. This result shows that there are similarities to substance and behavioral addictions. The absence of group differences and mixed results related to cognitive and sensorimotor systems raise concerns to what extent CSBD resembles a wide spectrum of impairments observed in disorders, and demand further research.
\end{abstract}

\section{KEYWORDS}

Compulsive Sexual Behavior Disorder, hypersexuality, cognitive processes, affective processes, behavioral addictions 


\section{INTRODUCTION}

\section{Compulsive Sexual Behavior Disorder}

In 2019, WHO published the 11th edition of International Classification of Diseases (ICD-11; World Health Organization, 2019), containing a new conceptualization of the Compulsive Sexual Behavior Disorder (CSBD) as an impulse control disorder. According to ICD-11, to fulfill the CSBD diagnostic criteria, patients must exhibit the following symptoms over a period of at least six months: (1) the patient shows persistent failure to control repetitive, intrusive strong sexual impulses, (2) various forms of compulsive sexual behavior are triggered by these impulses, (3) while sexual behavior is initially rewarding, it subsequently turns into a central focus of attention, which gives little or no satisfaction, but rather (4) harms the individual, and causes dysfunction and personal distress in important areas of life; (5) the patient continues to engage in the behavior, despite its negative consequences. In the absence of intensive distress affecting the patient's personal life or if the distress is related only to moral judgments and disapproval of sexual behavior (e.g. related to religious/moral beliefs), the diagnosis of CSBD is inapplicable (Kraus et al., 2018; World Health Organization, 2019).

\section{Modern approach to diagnosis - Research Domain Criteria}

There is an ongoing debate on the classification of CSBD as an impulse control disorder (Böthe et al., 2019; Gola \& Potenza, 2018; Potenza et al., 2017). This debate is related to the 19th-century medical approach proposed by Kraepelin (1883), who assumed that, for a certain disorder to be diagnosed, a specific combination of symptoms of the right intensity and temporal pattern must be observed, and that specific disorders based on similarity of symptoms can be grouped into distinct taxonomic units (mood disorders, psychotic disorders, addictions, etc.). Although this approach is still used in such prominent classifications of mental disorders as the Diagnostic and Statistical Manual of Mental Disorders (DSM) or the ICD, it has been criticized for its failure to describe the mechanisms underlying the disorders, the low predictability of therapeutic outcomes, and the lack of personalization in the light of increasing evidence for a heterogeneous character of nosological entities (Garvey, Avenevoli, \& Anderson, 2016; Kozak \& Cuthbert, 2016). To address these flaws, the Research Domain Criteria (RDoC; Insel et al., 2010) approach was developed. RDoC, proposed by the National Institute of Mental Health in the United States, is based on the assumption that mental disorders can be described on multiple levels, such as genetic, molecular, functional brain connectivity, psychophysiological, behavioral, and psychological. This approach can lead to a better and broader understanding of the mechanisms of the origin and persistence of mental disorders since such disorders are described in terms of specific mechanisms, rather than ambiguous phenomenological concepts (such as "depression" or "addiction"). Furthermore, each problem is described in six different domains of human functioning: (A) Negative Valence Systems, (B) Positive Valence Systems, (C) Cognitive Systems, (D) Systems for Social Processes, (E) Arousal or Regulatory Systems and (F) the Sensorimotor Systems (Garvey et al., 2016; Kozak \& Cuthbert, 2016; Sanislow et al., 2020). Based on the state of literature (see Table 1), we focus on four domains defined a priori $(\mathrm{A}, \mathrm{B}, \mathrm{C}$, and $\mathrm{F})$, which are considered as relevant to the understanding of the CSBD (Kwako, Momenan, Litten, Koob, \& Goldman, 2016; Romanczuk-Seiferth, van den Brink, \& Goudriaan, 2014).

Table 1. State of literature about functional deficits in CSBD

Research Domain Criteria (RDoC)

Negative Valence Systems Positive Valence Systems

Cognitive Systems

Sensorimotor System
Previously published results from behavioral studies

\section{No data}

- stronger motivation to receive erotic rewards in CSBD individuals (Gola et al., 2017),

- approach bias in favor of erotic stimuli correlated with pornography use measures (Sklenarik et al., 2019; Snagowski \& Brand, 2015; Stark et al., 2017),

- CSBD patients are more sensitive to novelty and respond more strongly to reward cues in the conditioning procedure (Banca, Morris, et al., 2016)

- in the group of CSBD patients, the processing of erotic stimuli is associated with stronger desire and increased activity in the dACC - ventral striatum - amygdala network (Brand et al., 2016; Voon et al., 2014) and the left caudate nucleus (Seok \& Sohn, 2015)

- CSBD patients have a greater enhanced attentional bias in trials with sexual stimuli (Mechelmans et al., 2014),

- no differences between CSBD patients and healthy controls in neuropsychological behavioral tasks, including the WAIS Intelligence Test, Color-Word Interference Test, Tower Test, Trail Making

Test, Verbal Fluency Test and Wisconsin Card Sorting Test (Reid, Garos, \& Carpenter, 2011; Reid, Garos, Carpenter, et al., 2011),

- no decrease in the level of cognitive flexibility or ability to switch attention in CSBD subjects (Banca, Harrison, et al., 2016)

- significant relationship between the level of task performance and the severity of CSBD symptoms (Antons \& Brand, 2018) 
Negative Valence Systems (A). It is known that CSBD individuals experience shame, self-aversion, and loneliness more frequently than healthy controls do and that CSBD symptoms are often accompanied by stress, negative emotions (Odlaug et al., 2013; Reid et al., 2014; Schreiber, Grant, \& Odlaug, 2012; Spenhoff, Kruger, Hartmann \& Kobs, 2013) and severe anxiety (Gola et al., 2015, Wordecha et al., 2018). Multiple researchers mention CSBD as a coping mechanism to self-regulate negative emotional states (Lew-Starowicz, Lewczuk, Nowakowska, Kraus, \& Gola, 2020; Miner, Dickenson, \& Coleman, 2019; Wordecha et al., 2018). Unfortunately, no behavioral or/and neuroimaging studies have been performed to compare the processing of negative stimuli in CSBD patients and healthy controls.

Positive Valence Systems (B). Positive Valence Systems describe responses to motivational situations, such as reward-seeking, consummatory behavior, and appetitive learning processes. Studies provide evidence for a stronger motivation to receive erotic rewards in CSBD individuals, and this effect can be observed both on the behavioral and neuronal levels (Gola et al., 2017). Evidence from the approach-avoidance task paradigm revealed that CSBD patients exhibit an approach bias in favor of erotic stimuli, which is correlated with pornography use measures (Sklenarik et al., 2019; Stark et al., 2017). In Snagowski and Brand (2015) study, a subclinical group of participants with CSBD symptoms tended to either approach or avoid pornographic stimuli, in contrast to neutral stimuli. Patients are more sensitive to novelty and respond more strongly to reward cues in the conditioning procedure (Banca, Morris, et al., 2016); furthermore, the amygdala is the only brain region that differentiates CSBD from healthy controls during the conditioning procedure (Klucken, Wehrum-Osinsky, Schweckendiek, Kruse, \& Stark, 2016). In CSBD patients the processing of erotic stimuli is associated with stronger desire and increased activity in the dACC-ventral striatumamygdala network (Brand, Snagowski, Laier, \& Maderwald, 2016; Voon et al., 2014) and the left caudate nucleus (Seok \& Sohn, 2015). Such individuals experience a much stronger desire towards sexual stimuli, which can be seen as a craving (Kraus, Voon, \& Potenza, 2016). It appears that studies of both A and B systems may help us understand the mechanisms involved in CSBD and related to emotional processing, such as crucial coping strategies, with both negative (e.g. shame, loneliness, anger) and positive (e.g. pleasure, positive arousal emotions conditioned by the increased need of erotic stimulation). In our view, these systems need to be studied more comprehensively, especially to provide insights - so far missing - into the workings of the negative system.

Cognitive Systems (C) and the Sensorimotor System (F). According to one hypothesis, CSBD individuals suffer from certain deficits in executive functions (impairment of control of sexual behavior, lack of inhibition of sexual impulses, difficulties in planning and decision making, as well as deficits in cognitive flexibility and other attentional biases) (Kor, Fogel, Reid, \& Potenza, 2013). These deficits could be described in the context of Cognitive Systems and the Sensorimotor System. So far, only several studies on this topic have been published. CSBD patients show greater sensitivity to pornographic content and some dysfunctions in the attention processes, specifically an early attentional bias in response to erotic cues (Mechelmans et al., 2014). A study published in 2011 failed to find any differences between CSBD patients and healthy controls in neuropsychological behavioral tasks (including the WAIS Intelligence Test, Color-Word Interference Test, Tower Test, Trail Making Test, Verbal Fluency Test and, Wisconsin Card Sorting Test), while in the Behavior Rating Inventory of Executive Function (BRIEF-A, Rabin et al., 2006) significantly lower scores were achieved by CSBD subjects on the subscales of attention switching, planning and emotional control (Banca, Harrison \& Voon, 2016b; Reid, Garos, \& Carpenter, 2011a; Reid, Garos, Carpenter, \& Coleman 2011b; Reid, Karim, McCrory \& Carpenter, 2010) also failed to observe any decrease in the level of cognitive flexibility or ability to switch attention in CSBD subjects.

Impulsivity is an important aspect of the Sensorimotor System. Studies investigating behavioral aspects of impulsivity have shown that CSBD patients have higher levels of non-planning impulsivity and average levels of attentional and motor impulsivity when compared to healthy controls (Miner et al., 2016). Unregulated pornography users also exhibit higher levels of craving, attentional impulsivity and, some dysfunctions in coping strategies and delay discounting compared to recreational users (Antons et al., 2019). Questionnaire studies have shown that impulsivity in CSBD patients is moderately and positively related to hypersexual behavior (Böthe et al., 2019) and that impulsivity-related features (e.g. risk-taking and sensation seeking) are weakly and positively correlated with self-reported positive and negative effects of pornography use (Wetterneck, Burgess, Short, Smith, \& Cervantes, 2012). Researchers found that trait impulsivity assessed by questionnaires was associated with higher symptom severity of internet pornography use, but this correlation was not significant in behavioral results from the Stop Signal Task (Antons \& Brand, 2018). It seems that CSBD is associated with some deficits in executive functions, e.g. attentional functions, switching, cognitive flexibility and, inhibition processes, but none of these deficits have been demonstrated in association with the problematic activity, i.e. when the presentation of erotic stimuli accompanies the learning processes. Our study fills this gap and expands our understanding of other important cognitive processes discussed in the literature.

\section{Aim of the study}

To the best of our knowledge, comprehensive data relevant to the multi-domain assessment of CSBD has never been collected. We believe that this kind of assessment is important because previous studies have always focused on one cognitive process at a time. Due to heterogeneity in sampling, it is hard to get a broad picture of cognitive deficits from a single sample. Moreover, many studies in the 
past used only self-report questionnaires; we propose to use questionnaires and behavioral tasks together. Therefore, to learn about the functional deficits related to CSBD symptoms, we decided to compare CSBD and HC in terms of emotional processing and interference, risk and ambiguity processing, reward processing, discounting, implicit learning, attention, impulsivity, and cognitive control. Whenever possible, we modified the tasks to enable the assessment of specific functions in both neutral and erotic contexts, as previous results demonstrated deficits in CSBD patients mainly by utilizing experiments involving only tasks with a CSBD specific context (e.g. erotic cues and rewards in Gola et al., 2017), rather than both erotic and neutral context (e.g. the battery of tasks used by Reid, Garos, \& Carpenter, 2011; Reid, Garos, Carpenter, et al., 2011).

\section{METHODOLOGY}

\section{Procedure and measurement}

Subjects were recruited among men seeking treatment for CSBD at clinics in Warsaw, Poland. Healthy controls (HC) were recruited online. For both group participation in the study were connected to the monetary gratification. All subjects completed questionnaires designed to measure symptoms of CSBD: the Sexual Addiction Screening Test (Gola, Wordecha, et al., 2016; Gola, Skorko, et al., 2016), the Brief Pornography Screening Test (Kraus et al., 2020), and the Hypersexual Behavior Inventory (Reid, Garos, \& Carpenter, 2011; Reid, Garos, Carpenter, et al., 2011). We also collected data from questionnaires measuring affective processing, compulsivity, and impulsivity: the Sensitivity to Punishment and Sensitivity to Reward Questionnaire (SPSRQ, Torrubia, Avila, Molto, \& Caseras, 2001; Wytykowska, Białaszek, \& Ostaszewski, 2014), the State-Trait Anxiety Scale (STAI, Spielberger, 1989; Wrześniewski, Sosnowski, \& Matusik, 2002), the Hospital Anxiety and Depression Scale (HADS, Zigmond \& Snaith, 1983), the Obsessive-Compulsive Inventory - Revised (OCI-R, Foa et al., 2002), and the Barratt Impulsivity Scale (BIS-11, Stanford et al., 2009; Grzesiak, Beszłej, \& Szechiński, 2008).

The main phase of the study was conducted at the Nencki Institute of Experimental Biology, Warsaw, Poland. During this phase participants completed eight computerbased behavioral tasks (to see the correspondence between tasks and RDoC domains look Table 2):

- Facial Discrimination Task (FDT; Hariri et al., 2002; Carre, Hyde, Neumann, Viding, \& Hariri, 2013; Nikolova, Bogdan, Brigidi, \& Hariri, 2012; Victor, Sansosti, Bowman \& Hariri, 2015) to measure deficits in processing social negative stimuli related to the Negative Valence System, found in addictions (see Fig. 1A),

- Risk and Ambiguity Task (RAT; Levy, Snell, Nelson, Rustichini, \& Glimcher, 2010; Pushkarskaya et al., 2015) to extend the available data on readiness to engage in certain activities under conditions introducing ambiguity and to confirm the propensity of CSBD patients to engage
Table 2. List of the used behavioral tasks in correspondence to Research Domain Criteria (RDoC)

\begin{tabular}{lc}
\hline RDoC domain & Task \\
\hline Negative Valence Systems & Facial Discrimination Task \\
& Risk and Ambiguity Task \\
& Emotional Stroop Task \\
Positive Valence Systems & Incentive Delay Task \\
& Sexual Discounting Task \\
Cognitive Systems & Emotional Stroop Task \\
Sensorimotor System & Learning Task \\
\hline
\end{tabular}

in risky behavior, as a function of the Negative Valence System (see Fig. 1B),

- Emotional Stroop Task with modified categories of emotions (EST; Dresler, Mériau, Heekeren, \& Van Der Meer, 2009) to detect any deficits in emotional processing of positive and negative stimuli related to both Valence Systems, found in addictions (see Fig. 1C),

- Incentive Delay Task (IDT; Gola et al., 2017; Sescousse, Barbalat, Domenech, \& Dreher, 2013) to observe appetitive processing of erotic and monetary cue and rewards as evidence of dysfunctions in the Positive Valence System, found previously also in gambling disorders (see Fig. 1D), - Sexual Discounting Task (SDT; Herrmann, Hand, Johnson, Badger, \& Heil, 2014; Johnson, Johnson, Herrmann \& Sweeney, 2015) to find deficits in reward discounting in the clinical sample as evidence of the defective function of the Positive Valence System (see Fig. 1E),

- Learning Task (LT; a modified version of De Berker et al., 2016) to detect deficits in the cognitive system's learning processes while receiving both erotic and non-erotic rewards, rather than only erotic ones, as in previous studies (see Fig. 1F),

- Attentional Network Task (ANT; Williams et al., 2016) to confirm the existence of cognitive dysfunctions in three attentional networks, found in addictions (see Fig. 1G);

- Stop Signal Task (SST; modified version of Aron \& Poldrack, 2006) to measure deficits in the Sensorimotor System, and also to confirm the validity of the hypothesis regarding higher impulsivity in CSBD patients, postulated in the nosological category of impulse control disorders (see Fig. 1H).

Descriptions of all the tasks are included in Section S1 of the supplementary materials.

The databases and the list of analysis in JASP software are available in the Open Science Framework repository on https://osf.io/7vtud/?view_only=73d1d2a11362429da593550 $86572 \mathrm{a} 699$.

\section{Participants}

Both groups consisted of heterosexual men: 74 CSBD patients and $66 \mathrm{HC}$ subjects matched by age, income, and handedness. Patients were initially interviewed by psychiatrists, who applied structured clinical interviews with the classification criteria for CSBD according to ICD-11 and 


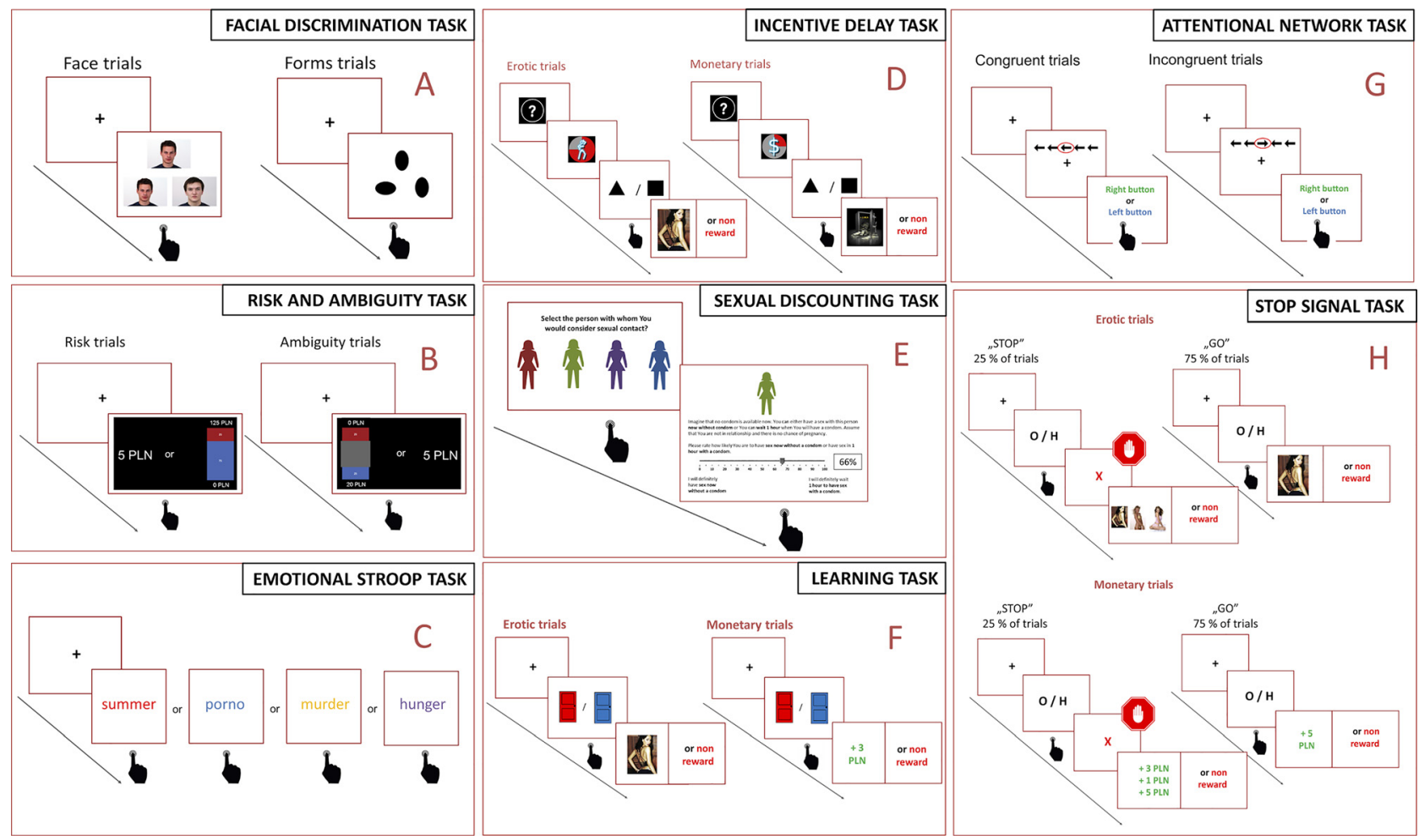

Fig. 1. The design of the eight tasks used in the present study.

FDT - 1A; the task consists of emotional and control blocks, in which subjects see three stimuli on the screen, one at the top and two below it, and are asked to choose which of the two lower stimuli corresponds to the upper one; FDT is designed to measure the processing of emotions, RAT - 1B; the participant is asked to bet in a lottery of various winning probability and ambiguity level, as well as various payoff amounts; the task is used to study the decision-making process under two conditions of uncertainty, involving either risk or ambiguity, EST - 1C; the emotional version of the Stroop Task, in which emotional words are displayed in various colors and the subject is asked to indicate the right color; the reaction time is significantly different if the words are emotionally charged (as opposed to neutral words), so that EST can be used to study emotions processing, IDT -1D; IDT consists of two phases: the cue phase (presentation of icons representing different types of rewards, with payoff value and probability of win) and the reward-processing phase (designed to measure the subjective hedonistic value of the reward); the two phases are separated by a discriminatory task (the subject must press a button as soon as possible in response to figures), which, if the correct key was pressed sufficiently fast, is followed by a reward displayed on the screen (either a picture of a naked woman in erotic trials, or a picture representing a sum of money in monetary trials), SDT - 1E; the participant estimates the risk of contracting a sexually transmitted disease for each hypothetical sexual partner, and also his readiness to have sex with the partner, either immediately but without a condom, or with a condom, but not immediately (with a delay varying from $1 \mathrm{~h}$ to 3 months); the task measures the discounting of sexual activity, LT - 1F; a blue or red door appears on the screen and the participant is asked to decide whether to open the door or not; after the decision a reward may be displayed (erotic or monetary), with a probability indicated by the color of the door; LT makes it possible to study the process of probability learning in the context of sexual/monetary rewards, ANT - 1G; a row of five arrows, pointing in the same or in different directions (congruent vs. incongruent), is presented and in trials the subject just marks the direction of the middle arrow, while in others the presentation of the arrows is preceded by a distractor, such as an asterisk shown on the screen or sound played as a warning signal; ANT is used to capture individual differences in putative attention networks (alerting, orienting and executive control), SST - 1H; the task consists of two types of trials (GO and STOP); in GO trials the participant presses the right or left button in response to the letter H or the letter O; in STOP trials a STOP mark (a red cross) appears after a specified delay and the participant must inhibit his reaction and refrain from pressing any button; SST can be used to measure impulsiveness, understood as the ability to inhibit an already initiated reaction)

Kafka (2010) criteria (all patients fulfilled at least 4 from 5 criteria). All CSBD participants fulfilled the classification of CSBD and were mainly suffering from extensive pornography use, some of them also exhibit excessive sexual dating behavior or other sexual activity. HC participants never experienced any psychiatric or neurological disorders. All subjects were screened for sexual orientation (exclusively or predominantly heterosexual orientation measured with the Polish adaptation of the Kinsey Scale: (Wierzba et al., 2015) and history of alcohol abuse (scores over 14, measured by the Alcohol Use Disorders Identification Test: Babor, de la
Fuente, Saunders, \& Grant, 1992) and problematic gambling (scores over 5, measured by the South Oaks Gambling Screen: Lesieur \& Blume, 1987) in the case of exclusion.

\section{Analysis of the dataset}

Data analysis was performed using MATLAB R2017a (The Math Works Inc. Natick, USA), the SPSS statistics package (link: https://www.ibm.com/products/spss-statistics), and JASP software (JASP Team, 2019). First, subject characteristics and questionnaire scores were compared using 
Table 3. Statistical tests used in the analysis

\begin{tabular}{|c|c|c|c|c|}
\hline Task & Within subject factors & $\begin{array}{l}\text { Between subject } \\
\text { factor }\end{array}$ & Statistical test & Variable of interest \\
\hline $\begin{array}{l}\text { Facial Discrimination Task } \\
\text { (Carre et al., 2013; } \\
\text { Nikolova et al., 2012) }\end{array}$ & $\begin{array}{l}4 \text { emotion categories (anger, } \\
\text { fear, surprise, neutral) }\end{array}$ & 2 groups & ANOVA $4 \times 2$ & $\begin{array}{l}\text { Response accuracy (percentage of } \\
\text { trials with incorrect matching or } \\
\text { trials without answer), reaction } \\
\text { time (mean reaction time in trials } \\
\text { with } 4 \text { emotion categories) }\end{array}$ \\
\hline $\begin{array}{l}\text { Risk and Ambiguity Task } \\
\text { (Levy et al., 2010; } \\
\text { Pushkarskaya et al., 2015) }\end{array}$ & 2 types of trials (win/lose) & 2 groups & ANOVA $2 \times 2$ & $\begin{array}{l}\text { Risk and ambiguity aversion } \\
\text { indicators (calculated in } \\
\text { accordance with Pushkarskaya et } \\
\text { al., 2015) }\end{array}$ \\
\hline $\begin{array}{l}\text { Emotional Stroop Task with } \\
\text { modified categories of } \\
\text { emotions (Dresler et al., } \\
\text { 2009) }\end{array}$ & $\begin{array}{l}5 \text { emotion categories (erotic, } \\
\text { appetitive but not erotic, } \\
\text { fearful, negative but not } \\
\text { fearful, neutral) }\end{array}$ & 2 groups & ANOVA $5 \times 2$ & $\begin{array}{l}\text { Response accuracy (percentage of } \\
\text { trials with incorrect matching or } \\
\text { trials without answer), reaction } \\
\text { time (mean reaction time in trials } \\
\text { with } 5 \text { emotion categories) }\end{array}$ \\
\hline $\begin{array}{l}\text { Incentive Delay Task (Gola } \\
\text { et al., 2017; Sescousse } \\
\text { et al., 2013) }\end{array}$ & $\begin{array}{c}2 \text { types of trials (erotic/ } \\
\text { monetary) } \\
2 \text { levels of reward value } \\
\text { (small/big) } \\
3 \text { levels of probability }(25 \%, \\
50 \%, 75 \%)\end{array}$ & 2 groups & $\begin{array}{c}\text { ANOVA } 2 \times 2 \times \\
3 \times 2\end{array}$ & $\begin{array}{l}\text { Response accuracy (percentage of } \\
\text { trials with incorrect matching or } \\
\text { trials without answer), reaction } \\
\text { time (mean reaction time in trials } \\
\text { with } 2 \text { types, } 2 \text { levels of reward } \\
\text { value and } 3 \text { levels of probability), } \\
\text { hedonic ratings (mean rate for } \\
\text { hedonic value in trials with } 2 \text { types, } \\
2 \text { levels of reward value and } 3 \text { levels } \\
\text { of probability) }\end{array}$ \\
\hline $\begin{array}{l}\text { Sexual Discounting Task } \\
\quad \text { (Herrmann et al., 2014) }\end{array}$ & & 2 groups & $t$-test & $\begin{array}{l}\text { Discounting parameters (the area } \\
\text { under the discounting curve for a } \\
\text { given condition: the most/the least } \\
\text { desirable partner to have sex with } \\
\text { or the most/the least likely to carry } \\
\text { a sexually transmitted infection, all } \\
\text { calculations based on Herrmann et } \\
\text { al., 2014) }\end{array}$ \\
\hline $\begin{array}{l}\text { Learning Task (modified } \\
\text { version of De Berker et al., } \\
\text { 2016) }\end{array}$ & $\begin{array}{c}2 \text { types of reward (erotic/ } \\
\text { monetary) }\end{array}$ & 2 groups & ANOVA $2 \times 2$ & $\begin{array}{l}\text { Response accuracy (percentage of } \\
\text { trials with incorrect matching or } \\
\text { trials without answer), reaction } \\
\text { time (mean reaction time in trials } \\
\text { with } 2 \text { types of reward), subject- } \\
\text { specific parameter of the response } \\
\text { model (calculation based on De } \\
\text { Berker et al., 2016) }\end{array}$ \\
\hline $\begin{array}{l}\text { Attentional Network Task } \\
\text { (Williams et al., 2016) }\end{array}$ & $\begin{array}{l}2 \text { types of alarm (no-alarm } \\
\text { trials/with-alarm trials), } \\
3 \text { types of cue (congruent } \\
\text { cue/incongruent cue/no } \\
\text { cue), } \\
2 \text { types of arrow direction } \\
\text { (congruent/incongruent) }\end{array}$ & 2 groups & $\begin{array}{c}\text { ANOVA } 2 \times 3 \times \\
2 \times 2\end{array}$ & $\begin{array}{l}\text { Response accuracy (percentage of } \\
\text { trials with incorrect matching or } \\
\text { trials without answer), reaction } \\
\text { time (mean reaction time in trials } \\
\text { with } 2 \text { types of alarm, } 3 \text { types of } \\
\text { cues, } 2 \text { types of direction } \\
\text { configuration) }\end{array}$ \\
\hline $\begin{array}{l}\text { Stop Signal Task (modified } \\
\text { version of Aron \& } \\
\text { Poldrack, 2006) }\end{array}$ & $\begin{array}{c}2 \text { types of reward (erotic/ } \\
\text { monetary) }\end{array}$ & 2 groups & ANOVA $2 \times 2$ & $\begin{array}{l}\text { Response accuracy (percentage of } \\
\text { trials with incorrect matching or } \\
\text { trials without answer), reaction } \\
\text { time (mean reaction time in trials } \\
\text { with } 2 \text { types of reward), mean value } \\
\text { of the Stop Signal Delay (mean } \\
\text { time of STOP stimulus delay } \\
\text { adjusted to task execution in } 3 \\
\text { types of trials) }\end{array}$ \\
\hline
\end{tabular}


Table 4. Variables describing subject groups

\begin{tabular}{|c|c|c|c|c|}
\hline & CSBD patients $N=74$ & Healthy controls $N=66$ & $P$-value & $t$-Statistic \\
\hline Age: mean (SD) & $34.42(7.80)$ & $32.86(7.41)$ & 0.2 & -1.20 \\
\hline Salary in PLN: mean (SD) & $5,331.08(4,475.34)$ & $4,582.27(3,572.13)$ & 0.3 & -1.09 \\
\hline SASTR (SD) & $11.19(3.50)$ & $2.59(1.64)$ & $<0.001$ & -18.76 \\
\hline BPS (SD) & $7.61(2.36)$ & $1.77(1.98)$ & $<0.001$ & -15.63 \\
\hline HBI total (SD) & $62.11(16.82)$ & - & - & - \\
\hline SOGS (SD) & $0.59(1.45)$ & $1.03(1.41)$ & 0.08 & 1.78 \\
\hline AUDIT (SD) & $6.65(4.36)$ & $6.49(3.56)$ & 0.8 & -0.22 \\
\hline SPSRQ Punishment Sensitivity (SD) & $6.34(3.27)$ & $3.53(3.39)$ & $<0.001$ & -4.98 \\
\hline SPSRQ Reward Sensitivity (SD) & $5.05(2.26)$ & $4.74(1.93)$ & 0.4 & -0.88 \\
\hline STAI Anxiety Trait (SD) & $49.11(2.79)$ & $47.91(2.63)$ & $<0.01$ & -2.62 \\
\hline STAI Anxiety State (SD) & $47.5(11.2)$ & $36.08(9.08)$ & $<0.001$ & -6.66 \\
\hline HADS Anxiety Scale (SD) & $9.82(4.04)$ & $5.36(2.84)$ & $<0.001$ & -7.62 \\
\hline HADS Depression Scale (SD) & $6.96(3.97)$ & $3.95(3.13)$ & $<0.001$ & -5 \\
\hline OCI Total Score (SD) & $17.01(9.29)$ & $12.44(7.34)$ & $<0.002$ & -3.25 \\
\hline BIS-11 Total Score (SD) & $67.76(11.12)$ & $62.15(9.46)$ & $<0.002$ & -3.22 \\
\hline
\end{tabular}

SASTR $=$ Sexual Addiction Screening Test - Revised version, BPS = Brief Pornography Screening Test, HBI = Hypersexual Behavior Inventory, SOGS = South Oaks Gambling Screen, AUDIT = Alcohol Use Disorders Identification Test, SPSRQ $=$ Sensitivity to Punishment and Sensitivity to Reward Questionnaire, STAI = State-Trait Anxiety Inventory, HADS = Hospital Anxiety and Depression Scale, OCI-R = Obsessive Compulsive Inventory- Revised version, BIS-11 = Barrat Impulsiveness Scale, SD = standard deviation.

independent $t$-tests. This was followed by comparative behavioral analyses between CSBD and HC, using independent $t$-tests and mixed-measures ANOVA tests (for details see Table 3). For a better understanding of the analyzed parameters, the Bayesian statistics method was also used. The introduction of this methodology is motivated by the fact that the traditional $P$-value approach only allows the null hypothesis to be accepted or rejected. However, it does not provide an opportunity to check whether the collected data favor the null hypothesis or the alternative hypothesis (Quintana \& Williams, 2018). For this reasons, Bayes Factors were calculated for all main effects and interactions. A Bayes Factor reflects how likely it is for data to arise from one model, as opposed to another model. The first model is the null hypothesis ( $\mathrm{HO}$ - no group differences/no interaction) and the other model is the alternative hypothesis (HA or H1). The Bayes Factor indicates the degree to which the data is more likely under $\mathrm{H} 0$ than under $\mathrm{H} 1$. Typically, researchers report BF10 or BFinclude values (meaning the evidence for the alternative hypothesis relative to the null hypothesis). In our study we reported BFinclude for ANOVAs or BF10 for $t$ tests, only when $P$-values are significant. But we also reported proportion of evidence for the null hypothesis relative to the alternative hypothesis i.e. BFexclude for ANOVAs or BF01for $t$-tests, when $P$-values are not significant. This allows us to interpret the results directly in terms of support for the null hypothesis if non-significant $P$-values are obtained in frequentist statistical analysis (Quintana \& Williams, 2018).

\section{Ethics}

Participants received detailed information about the aims of the study and were assured of the anonymity and confidentiality of their participation in the study. They all signed an informed consent form prior to the commencement of the experimental procedure. To ensure anonymity, a double-blind procedure was employed, the members of the research team responsible for data acquiring had no access to information about group allocation. All the procedures were carried out in accordance with the Declaration of Helsinki. The study was approved by the local ethics committee of the Institute of Psychology Polish Academy of Sciences.

\section{RESULTS}

Variables describing subject groups are presented in Table 4. CSBD patients score higher on scales measuring CSBD symptoms and also significantly higher on the Punishment Sensitivity subscale of SPSRQ, Trait and State subscale in STAI, Anxiety and Depression subscale in HADS, and achieve higher total score parameters in OCI and BIS-11. The majority of participants were in formal or informal relationships (in the CSBD group 59.5\% and controls $81.8 \%$ ), in CSBD group $31.1 \%$ of participants were during a separation or after divorce and $8.1 \%$ were single, in the HC group only $18.2 \%$ of participants were single. Also the majority of participants were employed (CSBD - 83.8\% and HC - 86.4\%). In the CSBD group $14.9 \%$ of patients had primary or secondary level of education, $78.4 \%$ ended education on a university level and $6.8 \%$ continue the education. Similarly to CSBD, in HC group most participants ended their education at a university level (77.2\%), only $12.1 \%$ continue their education and $9.1 \%$ had only primary or secondary level of education.

Using methods of frequentist statistics, we did not find any significant differences between CSBD and HC in the behavioral dataset. However, analysis using Bayesian methods produced some noteworthy results, particularly in two tasks, for which the results were clear, and four others, for which evidence was found concerning half of the parameters. Interactions between groups and conditions were significant only in IDT and showed higher motivation to 


\begin{tabular}{|c|c|c|c|c|c|}
\hline Task & Analyzed parameter & $\begin{array}{l}\text { The main effect of } \\
\text { condition }\end{array}$ & The main effect of group & $\begin{array}{l}\text { Interaction between group } \\
\text { and condition }\end{array}$ & Comments \\
\hline $\begin{array}{l}\text { Facial Discrimination } \\
\text { Task }\end{array}$ & $\begin{array}{c}\text { Accuracy } \\
\text { Mean reaction time }\end{array}$ & $\begin{array}{c}(\boldsymbol{F}(\mathbf{3}, \mathbf{3 3 6})=\mathbf{6 , 7 2 8} ; \boldsymbol{P}= \\
\mathbf{0 . 0 0 1})[\text { BFincl }=2310,173] \\
(\boldsymbol{F}(\mathbf{3}, \mathbf{3 3 6})=\mathbf{5 9 , 5 4 3 ;} \boldsymbol{P}= \\
\mathbf{0 . 0 0 1 )}[\text { BFincl }= \\
2,110 \mathrm{e}+32]\end{array}$ & $\begin{array}{l}(F(1,112)=0,622 ; P= \\
0.432)[B F e x c l=1,469] \\
(F(1,112)=1,378 ; P= \\
0.243)[B F e x c l=1,484]\end{array}$ & $\begin{array}{c}(F(3,336)=2,16 ; P= \\
0.116)[B F e x c l=2,51] \\
(F(3,336)=1,658 ; P= \\
0.182)[\text { BFexcl }=\mathbf{4 , 9 1 3}]\end{array}$ & $\begin{array}{l}\text { - No significant differences were } \\
\text { found between the two groups } \\
\text { and BFexclude stats were on an } \\
\text { uninformative level } \\
\text { - Significant main effects of the type of } \\
\text { emotion in both accuracy and reac- } \\
\text { tion time parameters } \\
\text { - Trials ordered from lowest to highest } \\
\text { accuracy: surprised, fearful, neutral, } \\
\text { angry faces } \\
\text { - Longest reaction times: neutral faces; } \\
\text { shortest: faces expressing anger and } \\
\text { fear } \\
\text { - No significant interaction between } \\
\text { group and emotions; parameter } \\
\text { BFstat supports the null hypothesis } \\
\text { for mean reaction time }\end{array}$ \\
\hline $\begin{array}{l}\text { Risk And Ambiguity } \\
\text { Task }\end{array}$ & $\begin{array}{l}\text { Risk aversion indicator } \\
\text { Ambiguity aversion in- } \\
\text { dicator }\end{array}$ & $\begin{array}{c}(\boldsymbol{F}(\mathbf{1}, \mathbf{1 3 7})=\mathbf{2 8 0 , 9 2 5 ;} \boldsymbol{P}= \\
\mathbf{0 . 0 0 1})[\text { BFincl }= \\
7,347 \mathrm{e}+45] \\
(\boldsymbol{F}(\mathbf{1}, \mathbf{1 3 7})=\mathbf{8 7 , 6 0 8} ; \boldsymbol{P}= \\
\mathbf{0 . 0 0 1})[\text { BFincl }= \\
6,785 \mathrm{e}+15]\end{array}$ & $\begin{array}{c}(F(1,137)=0,505 ; P= \\
0.479)[\text { BFexcl }=\mathbf{5 , 3 8 8}] \\
(F(1,137)=0,387 ; P= \\
0.535)[\text { BFexcl }=\mathbf{5 , 4 7 9}]\end{array}$ & $\begin{array}{c}(F(1,137)=0,007 ; P= \\
0.934)[\text { BFexcl }=\mathbf{5 , 8 4 9}] \\
(F(1,137)=0,003 ; P= \\
0.958)[\text { BFexcl }=\mathbf{5 , 5 2 1}]\end{array}$ & $\begin{array}{l}\text { - No group effects were found for any } \\
\text { parameter; BFexclude statistics sup- } \\
\text { port the null hypothesis for risk and } \\
\text { ambiguity aversion indicators } \\
\text { - Significant main effects of the type of } \\
\text { condition (both risk aversion indi- } \\
\text { cator and ambiguity aversion indi- } \\
\text { cator were higher in trials with a } \\
\text { win) }\end{array}$ \\
\hline Emotional Stroop Task & $\begin{array}{c}\text { Accuracy } \\
\text { Mean reaction time }\end{array}$ & $\begin{array}{c}(F(4,552)=0,561 ; P= \\
0.682)[\text { BFexcl }=\mathbf{2 0 6 , 8 9 8}] \\
(\mathbf{F}(\mathbf{4 , 5 5 2})=\mathbf{1 0 , 4 8} \boldsymbol{P}= \\
\mathbf{0 . 0 0 1})[\text { BFincl }= \\
318279,094]\end{array}$ & $\begin{array}{l}(F(1,138)=0,879 ; P= \\
0.35)[B F e x c l=3,228] \\
(F(1,138)=2,691 ; P= \\
0.103)[\text { BFexc }=1,177]\end{array}$ & $\begin{array}{c}(F(4,552)=0,332 ; P= \\
0.853)[\text { BFexcl }=\mathbf{9 1}, \mathbf{4 3 9}] \\
(F(4,552)=1,135 ; P= \\
0.337)[\text { BFexcl }=\mathbf{1 7 , 9 6 1}]\end{array}$ & $\begin{array}{l}\text { - No main effect of group; Bayes } \\
\text { Factors on anecdotal level } \\
\text { - No interaction between condition } \\
\text { and group; Bayesian statistics sup- } \\
\text { port H0 } \\
\text { - Significant main effect of condition } \\
\text { on RTs, driven by shorter RTs in } \\
\text { erotic trials compared to all other } \\
\text { types }\end{array}$ \\
\hline
\end{tabular}


- In the analysis of hedonic ratings two statistically significant in-

teractions between task conditions and group effect were also noted: firstly, the interaction of reward type and group (CSBD patients rated erotic rewards higher); secondly, statistically significant interaction between magnitude and group (in both groups big rewards were rated higher than small rewards), BFexclude in probability analysis supports $\mathrm{H} 0$ concerning the lack of interaction

Sexual Discounting Task Discounting in the category of the most desirable partner to have sex with

Discounting in the category of the least desirable partner to

have sex with

Discounting in the category of partner least likely to carry a sexually transmitted infection

Discounting in the

category of partner most likely to carry a sexually

transmitted infection

Learning Task
$-$

$(T(74)=-0.98 ; P=0.33)$

$[B F 01=2,778]$

$(T(83)=0.178 ; P=0.859)$

$[$ BF01 $=4,351]$

$-\quad(T(79)=-0.69 ; P=0.492)$

$[B F 01=3,512]$

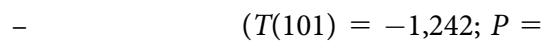

0.217) $[B F 01=2,422]$

$(F(1,138)=50,794 ; P=$

0.001) $[$ BFincl $=$

$1,244 \mathrm{e}+8]$

Mean reaction time

Subject-specific parameter of the response model
$F(1,138)=2,318 ; P=$

0.13) $[\mathrm{BFexcl}=2,549]$

$(F(1,138)=22,717 ; P=$

0.001) $[$ BFincl $=3754,319]$
$(F(1,138)=0,338 ; P=$ 0.562) $[\mathrm{BFexcl}=2,617]$

$(F(1,138)=0,203 ; P=$ 0.653) $[$ BFexcl = 3,560] $(F(1,138)=0,198 ; P=$ 0.657) $[$ BFexcl $=4,045]$
$(F(1,138)=0,685 ; P=$ 0.409) $[$ BFexcl $=3,751]$

$(F(1,138)=0,001 ; P=$ 0.991) $[$ BFexcl $=\mathbf{5}, 362]$ $(F(1,138)=0,105 ; P=$ $0.746)[$ BFexcl $=\mathbf{5 , 6 3}$
- In analysis of accuracy of prediction no group differences were found, and $\mathrm{BF}$ did not support $\mathrm{HO}$

- Analysis of prediction accuracy revealed a statistically significant effect of the condition (the parameter was higher in erotic trials than in monetary ones)

No statistically significant group differences were found, and BF01 did not support the null hypothesis for two of all four parameters 


\begin{tabular}{|c|c|c|c|c|}
\hline Task & Analyzed parameter & $\begin{array}{l}\text { The main effect of } \\
\text { condition }\end{array}$ & The main effect of group & $\begin{array}{c}\text { Interaction between group } \\
\text { and condition }\end{array}$ \\
\hline
\end{tabular}

- In subject-specific parameter analysis the main effect of the reward was also significant (the parameter was lower in erotic trials than in monetary ones)

- In RT analysis the main effect of the task was not significant, and BF was on anecdotal level

Attentional Network Task
Accuracy

(n)

Mean reaction time
For the 2 types of alarm: $(F(1,138)=5,085 ; P=$

For the 3 types of cue:

$(F(2,276)=62,239 ; P=$

0.001) $[\mathrm{BFincl}=$

$1,745 \mathrm{e}+19]$

For the 2 types of

direction: $(F(1,138)=$

127,63; $P=0.001$ ) [BFincl $=2,525 \mathrm{e}+70]$

For the 2 types of alarm: $(F(1,138)=236,585 ; P=$ 0.001) $[$ BFincl $=$

$$
1,648 \mathrm{e}+41]
$$

For the 3 types of cue:

$(F(2,276)=271,439 ; P=$

0.001) $[\mathrm{BFincl}=$

$$
1,946 \mathrm{e}+106
$$

For the 2 types of

direction: $(F(1,138)=$

856,734; $P=0.001$ )

$[$ BFincl $=$ infinity $]$
0.026) $[$ BFincl $=0,355]$
$(F(1,138)=1,258 ; P=\quad$ For the 2 types of alarm 0.264) $[$ BFexcl $=4,076]$ 0.767) $[$ BFexcl $=14,06$ For the 3 types of cue: $(F(2,276)=0,68 ; P=$ 0.48) $[$ BFexcl $=45,604$ For the 2 types of direction: $(F(1,138)=$ $1,015 ; P=0.316)[$ BFexcl

$$
=3,245]
$$

$(F(1,138)=0,49 ; P=$ 0.826) $[$ BFexcl $=2.81$

For the 2 types of alarm: $(F(1,138)=1,245 ; P=$ 0.266) $[$ BFexcl $=\mathbf{8 , 8 4 4}]$ For the 3 types of cue: $(F(2,276)=0,64 ; P=$ 0.509) $[$ BFexcl $=\mathbf{4 0 , 0 7 9}]$ For the 2 types of direction: $(F(1,138)=0,1$; $P=0.92)[B F e x c l=$ 13,256]
$(F(1,138)=0,088 ; P=$

- All interactions were not significant, with moderate BFexclude statistics

- No significant group differences in any of the analyzed parameters, but Bayes Factor in mean reaction time analysis on anecdotal level

- All main effects of the task's condition were significant

- Patterns of differences between conditions were similar in two parameters (accuracy and RTs): the parameters were lower in alarmed trials vs. not alarmed trials, a linear effect of the cue was found (the greatest number of errors and the slowest RT were in incongruent trials, followed by trials without cue; congruent trials produced the shortest RTs and the highest accuracy); RTs were shorter and accuracy was higher in trials with congruent directions of all arrows

(continued) 


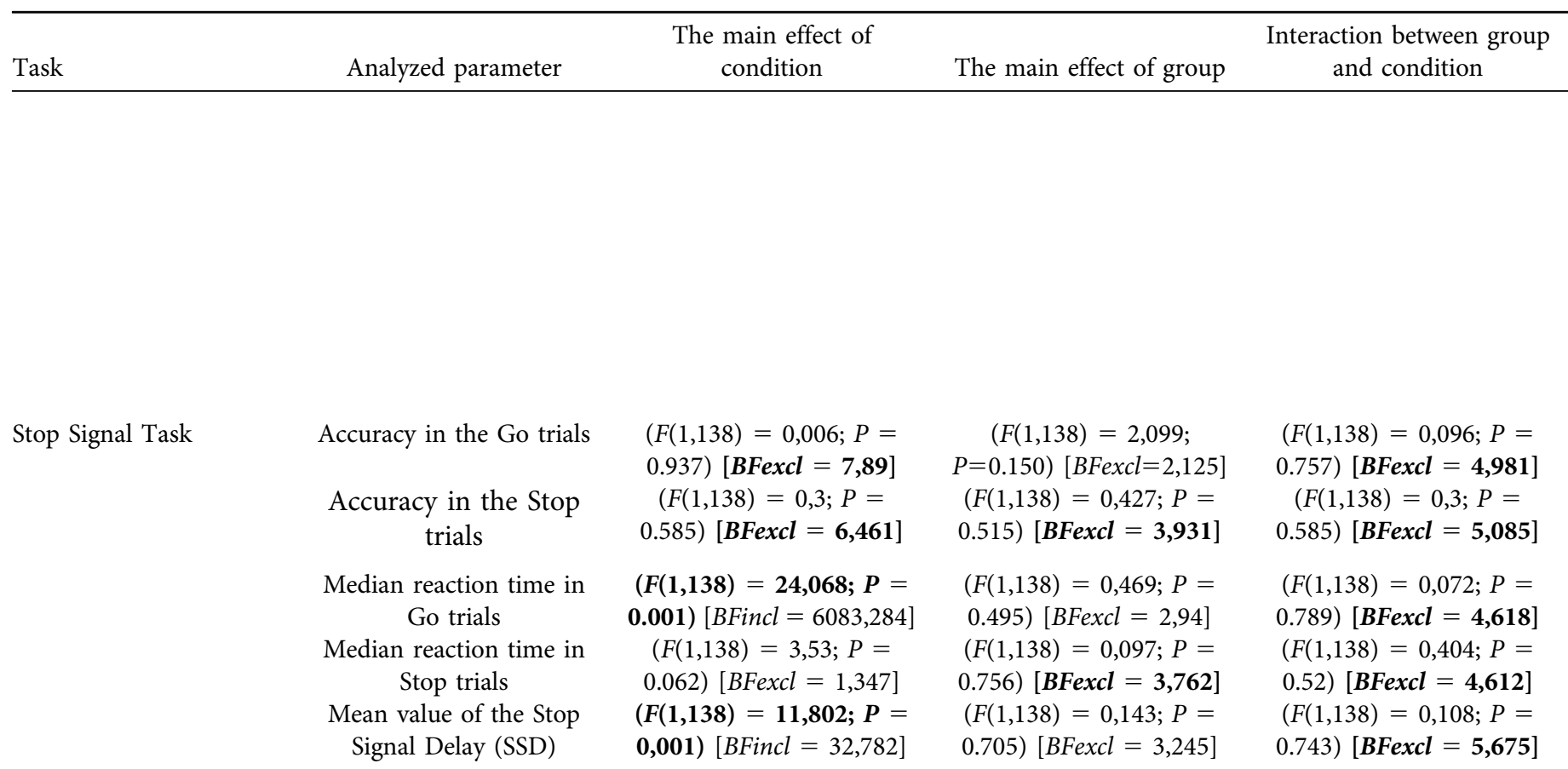

- There was no significant interaction between group and condition (for the accuracy parameter, BFexcl provides evidence in support of lack of interaction only in 3 types of cues; for reaction time analyses, lack of interaction was confirmed in three types of cues and two types of directions)

- We did not find any statistically significant group differences, and BFexclude statistics were on the anecdotal or low moderate level

- A significant main effect of the reward type was found for the median reaction time parameter in Go trials, and for the mean value of Stop Signal Delay (which was shorter in erotic trials than in monetary ones)

- There was no significant interaction between group and reward type, and Bayesian statistics provided moderate evidence for lack of interaction

We calculated two types of statistics: firstly, $F$ in ANOVA and t-statistic in $t$-tests; these are based on frequentist statistics and are given in parentheses (); secondly, statistics derived from Bayesian analysis are given in square brackets []. We report BFinclude for ANOVAs (and BF10 for $t$-tests) when $P$-values are significant and BFexclude for ANOVAs (or BF01 for $t$-tests) when $P$-values are not significant (significant results from frequentist statistical tests and BF01/BFexcl higher than 3,3 - evidence for the absence of group differences - are displayed in bold). 
Table 6. Summary of conclusions drawn from behavioral tasks, with comparison to previously published results

\begin{tabular}{|c|c|c|c|}
\hline $\mathrm{RDoC}$ domain & Task & Present study & Previously published results \\
\hline Negative Valence Systems & $\begin{array}{c}\text { Facial } \\
\text { Discrimination Task }\end{array}$ & $\begin{array}{l}\text { No differences between } \\
\text { patients and healthy controls } \\
\text { in processing of social negative } \\
\text { stimuli. }\end{array}$ & No data \\
\hline Negative Valence Systems & $\begin{array}{c}\text { Risk and Ambiguity } \\
\text { Task }\end{array}$ & $\begin{array}{l}\text { No differences between } \\
\text { patients and healthy controls } \\
\text { in aversion to risk or } \\
\text { ambiguous choice. }\end{array}$ & $\begin{array}{l}\text { Increased tendency to engage in risky behavior } \\
\text { in CSBD patients measured with the Iowa } \\
\text { Gambling Task (Mulhauser et al., 2014) }\end{array}$ \\
\hline $\begin{array}{l}\text { Negative and Positive Valence } \\
\text { Systems }\end{array}$ & $\begin{array}{c}\text { Emotional Stroop } \\
\text { Task }\end{array}$ & $\begin{array}{l}\text { Differences between patients } \\
\text { and healthy controls in } \\
\text { processing of positive and } \\
\text { negative stimuli. }\end{array}$ & $\begin{array}{l}\text { No data was recorded using the emotional } \\
\text { version of the task; study with the classic } \\
\text { version of the Stroop Task indicated impaired } \\
\text { accuracy in subclinical CSBD participants. }\end{array}$ \\
\hline Positive Valence Systems & Incentive Delay Task & $\begin{array}{l}\text { Differences between patients } \\
\text { and healthy controls in } \\
\text { processing appetitive rewards } \\
\text { and reward cues. }\end{array}$ & $\begin{array}{c}\text { Differences between patients and healthy } \\
\text { controls in processing appetitive rewards and } \\
\text { reward cues - Gola et al., 2017, using the same } \\
\text { behavioral task. }\end{array}$ \\
\hline Positive Valence Systems & $\begin{array}{l}\text { Sexual Discounting } \\
\text { Task }\end{array}$ & Inconclusive results. & $\begin{array}{l}\text { Negative correlation between time spent } \\
\text { viewing pornographic material and the ability } \\
\text { to discount rewards in a group of subclinical } \\
\text { participants (Negash et al., 2016). }\end{array}$ \\
\hline Cognitive Systems & Learning Task & $\begin{array}{l}\text { No differences between } \\
\text { patients and healthy controls } \\
\text { in learning processes. }\end{array}$ & $\begin{array}{l}\text { Studies that used the Approach-Avoidance } \\
\text { Task showed that participants with CSBD } \\
\text { symptoms tend to increase cognitive effort } \\
\text { through learning processes to obtain erotic } \\
\text { rewards (Sklenarik et al., 2019; Snagowski \& } \\
\text { Brand, 2015; Stark et al., 2017). }\end{array}$ \\
\hline Cognitive Systems & $\begin{array}{c}\text { Attentional Network } \\
\text { Task }\end{array}$ & Inconclusive results. & $\begin{array}{l}\text { A study with the Dot Probe Task produced the } \\
\text { following conclusions: CSBD patients have } \\
\text { greater enhanced attentional bias in trials with } \\
\text { sexual stimuli, while this effect is not observed } \\
\text { in neutral trials (Mechelmans et al., 2014) }\end{array}$ \\
\hline Sensorimotor System & Stop Signal Task & Inconclusive results. & $\begin{array}{c}\text { In a subclinical sample a significant relationship } \\
\text { between the level of task performance and the } \\
\text { severity of CSBD symptoms was shown } \\
\text { (Antons \& Brand, 2018). }\end{array}$ \\
\hline
\end{tabular}

win erotic rewards and higher hedonic value of erotic and large rewards in CSBD subjects. The complete list of results is presented in Table 5 .

\section{CONCLUSIONS}

The main aim of the study was to identify deficits in affective and cognitive systems among CSBD patients. To this end we used a dataset consisting of a set of questionnaires and eight computer-based behavioral tasks; we analyzed the data with the help of frequentist and Bayesian statistics. The dataset is unique in that it characterizes the CSBD sample utilizing a wide array of tasks, modified to include monetary and/or erotic context.

Questionnaire data revealed significant group differences in punishment sensitivity, state and trait of anxiety, level of depression, and intensity of compulsivity and impulsivity symptoms. Compared to HC, CSBD patients scored significantly higher on all sub-scales. Behavioral data was not that clear. Frequentist statistical tests revealed no significant differences between the examined groups in all analyzed parameters, but Bayesian methods provided evidence of the absence of group differences only in half of the parameters across all the tasks (for details, see Table 5, BFexclude and BFinclude values).

To be specific, analysis of behavioral data based on frequentist statistics revealed no significant group differences and no interactions between groups and conditions in seven out of eight tasks. Only in the Incentive Delay Task (IDT) interactions between groups and conditions were significant and showed a higher motivation to win erotic rewards and higher hedonic value of erotic and large rewards in CSBD patients, which replicates the results of our earlier study (Gola et al., 2017). In the Emotional Stroop Task (EST) and the Incentive Delay Task (IDT) no significant differences were found between the two groups in frequentist statistical tests; likewise, Bayes Factors provided no support for the null hypothesis for the most important variable, namely, reaction time (RT). In three tasks (Facial Discrimination Task (FDT), Risk and Ambiguity Task (RAT), and Learning Task (LT)), no significant group differences were found; the 
results of Bayesian analysis were uninformative or supported the null hypothesis (absence of differences between groups). The results of the Sexual Discounting Task (SDT), Attentional Network Task (ANT), and Stop Signal Task (SST) were inconclusive. Bayesian analysis of group differences in the performance of the SDT supports the null hypothesis for two out of four parameters; in the case of ANT BFs, half of the parameters support H0; for SST data, BFs were above 3,3 for two out of five parameters under analysis.

We believe that results from our experiments are a valuable source of information on affective and cognitive deficits in CSBD, though further research is needed to determine unequivocally whether there are significant differences between CSBD patients and healthy controls.

\section{DISCUSSION}

The results of our analysis show clearly that it is considerably easier to find significant differences between CSBD patients and healthy controls in questionnaire data than in behavioral datasets. This may be due to the fact that patients have low self-esteem and therefore misjudge their own traits. This effect was noticed also in other studies, e.g. Antons \& Brand, 2018; Reid et al. (2010), (2011a,b). It is also possible that questionnaires and tasks do not always measure overlapping constructs, e.g., it is possible that none of the tasks measured anxiety or depression. Also, task-based vs. questionnaire-based measures are often uncorrelated, even when overlapping constructs are measured (Pedroni et al., 2017; Wennerhold, Friese, \& Vazire, 2020). On the other hand, patterns of group differences in questionnaires were created on the basis of our clinical experience and previously published results (Gola et al., 2017; Mechelmans, et al., 2014; Odlaug, et al., 2013; Reid, Carpenter, Spackman, \& Willes, 2008; Schmidt et al., 2017; Seok \& Sohn, 2015; Voon et al., 2014; Wordecha et al., 2018), while the collection of behavioral data was an exploratory study, designed to develop fresh insights in a hitherto little-studied field.

The data collected from behavioral tasks were more mixed. Results from two tasks (Facial Discrimination Task (FDT) and Risk and Ambiguity Task (RAT)) (see Tables 5 and 6) could be clearly and unequivocally taken as evidence of the absence of differences between CSBD patients and HC in the domain of Negative Valence Systems, specifically in the processing of negative social stimuli, and an aversion to risk and ambiguous choice. The Facial Discrimination Task has never been used in a study of CSBD patients before. The Risk and Ambiguity Task has never been used before either, though a similar task, the Iowa Gambling Task, was used by Mulhauser et al. (2014), who showed that CSBD patients are more willing to engage in risky behavior. Differences between the CSBD and HC groups were demonstrated in the emotional version of the Stroop Task. Previous studies based on the classic version of the Stroop task (Seok \& Sohn, 2018) found lower accuracy and impaired executive control in the subclinical group with CSBD symptoms, compared to HC. Some evidence for difficulties in processing negative emotions and inability to cope with negative affective states among CSBD patients is provided by studies using ecological momentary assessment (Miner et al., 2019; Wordecha et al., 2018).

The Incentive Delay Task was previously used by Gola et al. (2017) and produced similar results as the present study. Our results from other tasks measuring the functions of the Positive Valence System (i.e. the Sexual Discounting Task (SDT)) were inconclusive. SDT measures the ability to postpone gratification in the form of sexual contact; this has not been studied before, except for one correlation study (Negash, Sheppard, Lambert, \& Fincham, 2016), in which the relationship between the time spent viewing pornographic material and the ability to discount monetary gratification was investigated; Negash showed that continued exposure to the immediate gratification of pornography is related to higher discounting of delayed rewards in the subclinical group of participants. Two domains related to cognitive processes (Sensorimotor System and Cognitive Systems) were assessed utilizing three tasks - Learning Task (LT), Attentional Network Task (ANT), and Stop Signal Task (SST) - but the results proved ambiguous. Learning deficits in the CSBD group were previously investigated using the Approach-Avoidance Task. It appears that people who experience CSBD symptoms tend to increase cognitive effort through learning processes to obtain erotic rewards (Sklenarik et al., 2019, 2020; Snagowski \& Brand, 2015; Stark et al., 2017). However, it is worth noting that the Learning Task was used in the study to examine only the learning process relevant to erotic and monetary rewards; it is not known what this process would be like in both groups if the task included the aspect of punishment (negative feedback) or if the paradigm of probabilistic reversal learning was used.

The Attentional Network Task is a tool for measuring dysfunctions in attentional systems. The similar Dot Probe Task was used in research on CSBD to measure the selectivity of attention during the processing of specific sexual stimuli. The results of this study showed that CSBD patients have a greater enhanced attentional bias in trials with sexual stimuli. This effect was not observed in neutral trials (Mechelmans et al., 2014). The SST task in the erotic version (the erotic context introduced not as a reward for correct responses, but as a distractor) has already been used to study the relationship between CSBD symptoms and the ability to inhibit the reaction. The results of this study showed a significant relationship between the level of task performance and the severity of CSBD symptoms (Antons \& Brand, 2018). However, the study was performed on a subclinical group, not a clinical population of CSBD patients, as in our study.

\section{Limitations}

Despite a large sample and sophisticated methodology, our study does have some limitations. Only heterosexual males aged between 21 and 55 years resident in XXX were recruited. In future research, greater diversity would be needed. Another important limitation is connected with the fact that CSBD seems to be a heterogenetic disorder, which 
causes different stages of impairment in each patient. Furthermore, sensitivity and test-retest reliability of the tasks was not tested in the study; such analyses were carried out for addiction, for example (Kräplin, Scherbaum, Bühringer, \& Goschke, 2016), but not for CSBD.

Funding sources: This study was supported by the Polish National Science Centre grants PRELUDIUM (2016/23/N/ HS6/02906) (for MD) funding data collection from CSBD subjects and OPUS grant (2014/15/B/HS6/03792) (for MG) funding data collection from controls subjects. NCN had no role in the study design, collection, analysis, or interpretation of the data, writing the manuscript, or the decision to submit the paper for publication.

Authors' contribution: MD contributed to study and methods design, subject recruitment, conducting data collection, data analysis and interpretation, manuscript writing, and obtaining funding. GS contributed to data analysis and interpretation and manuscript writing. MW contributed to preparing the tasks and contributed to the data analysis. KO, ISz, WZ̈, $\mathrm{AM}, \mathrm{EK}, \mathrm{JSz}, \mathrm{UH}, \mathrm{MT}, \mathrm{KG}, \mathrm{IA}, \mathrm{KSz}$ helped with data collection. MG contributed to study and methods design, data interpretation, manuscript writing, obtaining funding. All authors approved the final manuscript.

Conflict of interest: The authors report no conflicts of interest with respect to the content of this manuscript.

Acknowledgements: We are grateful to all participants who agreed to be involved in this study and to Maciej Skorko and Adam Łapiński from PredictWatch.com for access to PredictWatch's online platform for questionnaire and behavioral data collection.

\section{SUPPLEMENTARY DATA}

Supplementary data to this article can be found online at https://doi.org/10.1556/2006.2021.00056.

\section{REFERENCES}

Antons, S., \& Brand, M. (2018). Trait and state impulsivity in males with tendency towards internet-pornography-use disorder. Addictive Behaviors, 79, 171-177. https://doi.org/10.1016/j. addbeh.2017.12.029.

Antons, S., Mueller, S. M., Wegmann, E., Trotzke, P., Schulte, M., \& Brand, M. (2019). Facets of impulsivity and related aspects differentiate among recreational and unregulated use of internet pornography. Journal of Behavioral Addictions, 1-11. https:// doi.org/10.1556/2006.8.2019.22.

Aron, A. R., \& Poldrack, R. A. (2006). Cortical and subcortical contributions to stop signal response inhibition: Role of the subthalamic nucleus. The Journal of Neuroscience, 26(9),
2424-2433. https://doi.org/10.1523/JNEUROSCI.4682-05. 2006.

Babor, T. F., de la Fuente, J. R., Saunders, J., \& Grant, M. (1992) AUDIT. The alcohol use disorders identification test. Guidelines for use in primary health care. Geneva, Switzerland: World Health Organization.

Banca, P., Morris, L. S., Mitchell, S., Harrison, N. A., Potenza, M. N., \& Voon, V. (2016a). Novelty, conditioning and attentional bias to sexual rewards. Journal of Psychiatric Research, 72(11), 91-101.

Banca, P., Harrison, N. A., \& Voon, V. (2016b). Compulsivity across the pathological misuse of drug and non-drug rewards. Frontiers in Behavioral Neuroscience, 10(8), 154.

Bőthe, B., Tóth-Király, I., Potenza, M. N., Griffiths, M. D., Orosz, G., \& Demetrovics, Z. (2019). Revisiting the role of impulsivity and compulsivity in problematic sexual behaviors. The Journal of Sex Research, 56(2), 166-179. https://doi.org/10.1080/ 00224499.2018.1480744.

Brand, M., Snagowski, J., Laier, C., \& Maderwald, S. (2016). Ventral striatum activity when watching preferred pornographic pictures is correlated with symptoms of internet pornography addiction. Neuroimage, 129, 224-232. https://doi.org/10.1016/j. neuroimage.2016.01.033.

Carre, J. M., Hyde, L. W., Neumann, C. S., Viding, E., \& Hariri, A. R. A. (2013). The neural signatures of distinct psychopathic traits. Social Neuroscience, 8(2), 37-41. https://doi.org/10.1080/ 17470919.2012.703623.

De Berker, A., Rutledge, R. B., Mathys, C., Marshall, L., Cross, G., Dolan, R., \& Bestmann, S. (2016). Computations of uncertainty mediate acute stress responses in humans. Nature Communications, 7, 10996. https://doi.org/10.1038/ncomms10996.

Dresler, T., Mériau, K., Heekeren, H. R., \& Van Der Meer, E. (2009). Emotional stroop task: Effect of word arousal and subject anxiety on emotional interference. Psychological Research, 73(3), 364-371. https://doi.org/10.1007/s00426-0080154-6.

Foa, E. B., Huppert, J. D., Leiberg, S., Hajcak, G., Langner, R., Kichic Hajcak, G., \& Salkovskis, P. M. (2002). The Obsessive Compulsive Inventory: Development and validation of a short version. Psychological Assessment, 14, 485-496. https://doi.org/ 10.1037/1040-3590.14.4.485.

Garvey M., Avenevoli S., \& Anderson K. (2016). The National Institute of Mental Health research domain criteria and clinical research in child and adolescent psychiatry. Journal of the American Academy of Child and Adolescent Psychiatry, 55, 93-98. https://doi.org/10.1016/j.jaac.2015.11.002

Gola, M., Miyakoshi, M., \& Sescousse, G. (2015). Sex, impulsivity and anxiety: Interplay between ventral striatum and amygdala reactivity in problematic sexual behaviors. Journal of Neuroscience, 35(46), 15227-15229. https://doi.org/10.1523/ JNEUROSCI.3273-15.2015.

Gola, M., \& Potenza, M. N. (2018). The proof of the pudding is in the tasting: Data are needed to test models and hypotheses related to compulsive sexual behaviors. Archives of Sexual Behavior, 47(5), 1323-1325. https://doi.org/10.1007/s10508018-1167-x.

Gola, M., Skorko, M., Kowalewska, E., Kołodziej, A., Sikora, M., Wodyk, M., ... Dobrowolski, P. (2016b). Polska adaptacja testu 
przesiewowego na uzależnienie od zachowań seksualnych (Sexual Addiction Screening Test - revised) SAST-PL-M. Psychiatria Polska.

Gola, M., Wordecha, M., Marchewka, A., \& Sescousse, G. (2016a). Visual sexual stimuli-cue or reward? A perspective for interpreting brain imaging findings on human sexual behaviors. Frontiers in Human Neuroscience, 10(402), 1-7.

Gola, M., Wordecha, M., Sescousse, G., Lew-Starowicz, M., Kossowski, B., Wypych, M., . . . Marchewka, A. (2017). Can pornography be addictive? An fMRI study of men seeking treatment for problematic pornography use. Neuropsychopharmacology: Official Publication of the American College of Neuropsychopharmacology, 42, 2021. Retrieved from https://doi.org/10.1038/npp.2017.78.

Grzesiak, M., Beszłej, J. A., \& Szechiński, M. (2008). Skala impulsywności Barratta. Postępy Psychiatrii i Neurologii 2008; 17(1), 6164.

Hariri, A. R., Tessitore, A., Mattay, V. S., Fera, F., \& Weinberger, D. R. (2002). The amygdala response to emotional stimuli: A comparison of faces and scenes. Neuroimage, 17(1), 317-323. https://doi.org/10.1006/nimg.2002.1179.

Herrmann, E. S., Hand, D. J., Johnson, M. W., Badger, G. J., \& Heil, S. H. (2014). Examining delay discounting of condom-protected sex among opioid-dependent women and non- drugusing control women. Drug and Alcohol Dependence, 144, 5360. https://doi.org/10.1016/j.drugalcdep.2014.07.026.

Insel, T., Cuthbert, B., Garvey, M., Heinssen, R., Pine, D. S., Quinn, K., \& Wang, P. (2010). Research domain criteria (RDoC): Toward a new classification framework for research on mental disorders. American Journal of Psychiatry, 167, 748-751. https://doi.org/10.1176/appi.ajp.2010.09091379.

JASP Team (2019). JASP (Version 0.11.1) (Computer software).

Johnson, M. W., Johnson, P. S., Herrmann, E. S., \& Sweeney, M. M. (2015). Delay and probability discounting of sexual and monetary outcomes in individuals with cocaine use disorders and matched controls. PloS One, 10(5), 1-21. https://doi.org/10. 1371/journal.pone.0128641.

Kafka, M. P. (2010). Hypersexual disorder: A proposed diagnosis for DSM-V. Archives of Sexual Behavior, 39(2), 377-400. https://doi.org/10.1007/s10508-009-9574-7.

Klucken, T., Wehrum-Osinsky, S., Schweckendiek, J., Kruse, O., \& Stark, R. (2016). Altered appetitive conditioning and neural connectivity in subjects with compulsive sexual behavior. Journal of Sexual Medicine, 13(4), 627-636. https://doi.org/10. 1016/j.jsxm.2016.01.013.

Kor, A., Fogel, Y., Reid, R. C., \& Potenza, M. N. (2013). Should hypersexual disorder be classified as an addiction? Sexual Health \& Compulsivity, 20(1-2), 27-47. https://doi.org/10. 1080/10720162.2013.768132.

Kozak, M. J., \& Cuthbert, B. N. (2016). The NIMH research domain criteria initiative: Background, issues, and pragmatics. Psychophysiology, 53(3), 286-297. https://doi.org/10.1111/psyp. 12518.

Kraepelin, E. (1883) Compendium der Psychiatrie zum Gebrauche für Studirende und Aerzte (Leipzig: Abel); also later editions, as Psychiatrie. Ein kurzes Lehrbuch für Studirende und Aerzte.

Kräplin, A., Scherbaum, S., Bühringer, G., \& oschke, T. (2016). Retest reliabilities of decision-making and 554 cognitive control measures in addictive disorders. Sucht, 62, 191-202. https://doi. org/10.1024/0939-5911/a000430.

Kraus, S. W., Gola, M., Grubbs, J. B., Kowalewska, E., Hoff, R. A., Lew-Starowicz, M., . . Potenza, M. N. (2020). Validation of a brief pornography screen across multiple samples, Journal of Behavioral Addictions, 9(2), 259-271. Retrieved from Sep 17, 2020. https://doi.org/10.1556/2006.2020.00038.

Kraus, S. W., Krueger, R. B., Briken, P., First, M. B., Stein, D. J., Kaplan, M. S., . . . Reed, G. M. (2018). Compulsive sexual behaviour disorder in the ICD-11. World Psychiatry, 17, 109110. https://doi.org/10.1002/wps.20499.

Kraus, S. W., Voon, V., \& Potenza, M. N. (2016). Should compulsive sexual behavior be considered an addiction? Addiction. https://doi.org/10.1111/add.13297.

Kwako, L. E., Momenan, R., Litten, R. Z., Koob, G. F., \& Goldman, D. (2016). Addictions neuroclinical assessment: A neuroscience-based framework for addictive disorders. Biological Psychiatry, 80(3), 179-189. https://doi.org/10.1016/j.biopsych. 2015.10.024.

Lesieur, H. R., \& Blume, S. B. (1987). The South Oaks gambling screen (SOGS): A new instrument for the identification of pathological gamblers. The American Journal of Psychiatry, 144(9), 1184-1188.

Levy, I., Snell, J., Nelson, A. J., Rustichini, A., \& Glimcher, P. W. (2010). Neural representation of subjective value under risk and ambiguity. Journal of Neurophysiology, 103(2), 1036-1047. https://doi.org/10.1152/jn.00853.2009.

Lew-Starowicz, M., Lewczuk, K., Nowakowska, I., Kraus, S., \& Gola, M. (2020). Compulsive sexual behavior and dysregulation of emotion. Sexual Medicine Reviews, 8(2), 191-205. https://doi. org/10.1016/j.sxmr.2019.10.003.

Mechelmans, D. J., Irvine, M., Banca, P., Porter, L., Mitchell, S., Mole, T. B., \& Voon, V. (2014). Enhanced attentional bias towards sexually explicit cues in individuals with and without compulsive sexual behaviours. PloS One, 9(8). https://doi.org/ 10.1371/journal.pone.0105476.

Miner M. H., Dickenson, J., \& Coleman E. (2019). Effects of emotions on sexual behavior in men with and without hypersexuality. Sexual Addiction \& Compulsivity, 26(1-2), 24-41. https://doi.org/10.1080/10720162.2018.1564408.

Miner, M. H., Romine, R. S., Raymond, N., Janssen, E., MacDonald, A., \& Coleman, E. (2016). Understanding the personality and behavioral mechanisms defining hypersexuality in men who have sex with men. Journal of Sexual Medicine, 13, 1323-1331. https://doi.org/10.1016/j.jsxm.2016.06.015.

Mulhauser, K. R. W., Struthers, W. M., Hook, J. N., Pyykkonen, B. A., Womack, S. D., \& MacDonald, M. (2014). Performance on the Iowa gambling task in a sample of hypersexual men. Sexual Addiction \& Compulsivity, 21(2), 170-183. https://doi.org/10. 1080/10720162.2014.908333.

Negash, S., Sheppard, N. V. N., Lambert, N. M., \& Fincham, F. D. (2016). Trading later rewards for current pleasure: Pornography consumption and delay discounting. The Journal of Sex Research, 53(6), 689-700. https://doi.org/10.1080/00224499.2015.1025123.

Nikolova, Y. S., Bogdan, R., Brigidi, B. D., \& Hariri, A. R. (2012). Ventral striatum reactivity to reward and recent life stress interact to predict positive affect. Biological Psychiatry, 72, 157163. https://doi.org/10.1016/j.biopsych.2012.03.014. 
Odlaug, B. L., Lust, K., Schreiber, L. R., Christenson, G., Derbyshire, K., Harvanko, A., \& Grant, J. E. (2013). Compulsive sexual behavior in young adults. Annals of Clinical Psychiatry, 25, 193-200.

Pedroni, A., Frey, R., Bruhin, A., Dutilh, G., Hertwig, R., \& Rieskamp, J. (2017). The risk elicitation puzzle. Nature Human Behaviour, 1(11), 803-809. https://doi.org/10.1038/s41562-0170219-x.

Potenza, M. N., Gola, M., Voon, V., Kor, A., \& Kraus, S. W. (2017). Is excessive sexual behaviour an addictive disorder? The Lancet Psychiatry, 4, 663-664. https://doi.org/10.1016/S2215-0366(17) 30316-4.

Pushkarskaya, H., Tolin, D., Ruderman, L., Kirshenbaum, A., Kelly, J. M., Pittenger, C., \& Levy, I. (2015). Decision-making under uncertainty in obsessive-compulsive disorder. Journal of Psychiatric Research, 69(November), 166-173. https://doi.org/10. 1016/j.jpsychires.2015.08.011.

Quintana, D. S., \& Williams, D. R. (2018). Bayesian alternatives for common null-hypothesis significance tests in psychiatry: A non-technical guide using JASP. BMC Psychiatry, 18, 178. https://doi.org/10.1186/s12888-018-1761-4.

Rabin, L. A., Roth, R. M., Isquith, P. K., Wishart, H. A., NutterUpham, K. E., \& Pare, N. (2006). Self- and informant reports on executive function on the BRIEF-A in MCI and older adults with cognitive complaints. Archives of Clinical Neuropsychology, 21(7), 721-732. https://doi.org/10.1016/j.acn.2006. 08.004 .

Reid, R. C., Carpenter, B. N., Spackman, M., \& Willes, D. L. (2008). Alexithymia, emotional instability, and vulnerability to stress proneness in patients seeking help for hypersexual behavior. Journal of Sex \& Marital Therapy, 34(2), 133-149. https://doi. org/10.1080/00926230701636197.

Reid, R. C., Garos, S., \& Carpenter, B. N. (2011a). Reliability, validity, and psychometric development of the Hypersexual Behavior Inventory in an outpatient sample of men. Sexual Addiction \& Compulsivity, 18, 30-51. https://doi.org/10.1080/ 10720162.2011.555709.

Reid, R. C., Garos, S., Carpenter, B. N., \& Coleman, E. (2011b). A surprising finding related to executive control in a patient sample of hypersexual men. Journal of Sexual Medicine, 8(8), 2227-2236.

Reid, R. C., Karim, R., McCrory, E., \& Carpenter, B. N. (2010). Selfreported differences on measures of executive function and hypersexual behavior in a patient and community sample of men. International Journal of Neuroscience, 120(2), 120-127.

Reid, R. C., Temko, J, Moghaddam, J. F., \& Fong, T. W. (2014). Shame, rumination, and self-compassion in men assessed for hypersexual disorder. Journal of Psychiatric Practice, 20(4), 260-8. https://doi.org/10.1097/01.pra.0000452562.98286.c5.

Romanczuk-Seiferth, N., van den Brink, W., \& Goudriaan, A. E. (2014). From symptoms to neurobiology: Pathological gambling in the light of the new classification in DSM-5. Neuropsychobisesology, 95-102. https://doi.org/10.1159/ 000362839 .

Sanislow, C. A., Morris, S. E., Pacheco, J., \& Cuthbert, B. N. (2020). The National Institute of Mental Health Research domain criteria: An alternative framework to guide psychopathology research. In Geddes, J. R., Andreasen, N. C., \& Goodwin, G. M.
(Eds.), The new Oxford textbook of psychiatry (3rd ed.). Oxford, UK: Oxford University Press.

Schmidt, C., Morris, L., Kvamme, T. L., Hall, P., Birchard, T., \& Voon, V. (2017). Compulsive sexual behavior: Prefrontal and limbic volume and interactions. Human Brain Mapping, 38, 1182-1190. https://doi.org/10.1002/hbm.23447.

Schreiber, L. R., Grant, J. E., \& Odlaug, B. L. (2012). Emotion regulation and impulsivity in young adults. Journal of Psychiatric Research, 46, 651-658. https://doi.org/10.1016/j.jpsychires. 2012.02.005.

Seok, J. W., \& Sohn, J. H. (2015) Neural substrates of sexual desire in individuals with problematic hypersexual behavior. Frontiers in Behavioral Neuroscience, 9, 321. https://doi.org/10.3389/ fnbeh.2015.00321.

Seok, J. W., \& Sohn, J. H. (2018). Altered prefrontal and inferior parietal activity during a stroop task in individuals with problematic hypersexual behavior. Frontiers in Psychiatry, 9, 460. https://doi.org/10.3389/fpsyt.2018.00460.

Sescousse, G., Barbalat, G., Domenech, P., \& Dreher, J. C. (2013). Imbalance in the sensitivity to different types of rewards in pathological gambling. Brain: A Journal of Neurology, 136, 2527-2538. https://doi.org/10.1093/brain/awt126.

Sklenarik, S., Potenza, M. N., Gola, M., \& Astur, R. S. (2020). Approach bias for erotic stimuli among heterosexual female college students who use pornography. Addictive Behaviors, 106438. https://doi.org/10.1016/j.addbeh.2020.106438.

Sklenarik, S., Potenza, M. N., Gola, M., Kor, A., Kraus, S. W., \& Astur, R. S. (2019). Approach bias for erotic stimuli in heterosexual male college students who use pornography. Journal of Behavioral Addictions, 8(2), 234-241. https://doi.org/10. 1556/2006.8.2019.31.

Snagowski, J., \& Brand, M. (2015). Symptoms of cybersex addiction can be linked to both approaching and avoiding pornographic stimuli: Results from an analog sample of regular cybersex users. Frontiers in Psychology, 6(653), 1-14. https://doi.org/10. 3389/fpsyg.2015.00653.

Spenhoff, M., Kruger, T. H., Hartmann, U., \& Kobs, J. (2013). Hypersexual behavior in an online sample of males: Associations with personal distress and functional impairment. The Journal of Sexual Medicine, 10, 2996-3005. https://doi.org/10. $1111 /$ jsm. 12160.

Spielberger, C. D. (1989). State-trait anxiety inventory: bibliography. Consulting Psychologists Press.

Stanford, M. S., Mathias, C. W., Dougherty, D. M., Lake, S. L., Anderson, N. E., \& Patton, J. H. (2009). Fifty years of the Barratt impulsiveness scale: An update and review. Personality and Individual Differences, 47, 385-395. https://doi.org/10. 1016/j.paid.2009.04.008.

Stark, R., Kruse, O., Snagowski, J., Brand, M., Walter, B., Klucken, T., \& Wehrum-Osinsky, S. (2017). Predictors for (problematic) use of Internet sexually explicit material: Role of trait sexual motivation and implicit approach tendencies towards sexually explicit material. Sexual Addiction \& Compulsivity, 24(3), 180-202. https://doi.org/10.1080/10720162.2017. 1329042.

Torrubia, R., Avila, C., Molto, J., \& Caseras, X. (2001). The sensitivity to punishment and sensitivity to reward questionnaire (SPSRQ) as a measure of Gray's anxiety and impulsivity 
dimensions. Personality and Individual Differences, 31, 837862. https://doi.org/10.1016/S0191-8869(00)00183-5.

Torrubia, R, Ávila, C, Moltó, J, \& Caseras, X (2001). The Sensitivity to Punishment and Sensitivity to Reward Questionnaire (SPSRQ) as a measure of Gray's anxiety and impulsivity dimensions. Personality and Individual Differences, 31, 837-862.

Victor, E. C., Sansosti, A. A., Bowman, H. C., \& Hariri, A. R. (2015). Differential patterns of amygdala and ventral striatum activation predict gender-specific changes in sexual risk behavior. Journal of Neuroscience, 35(23), 8896-8900. https:// doi.org/10.1523/JNEUROSCI.0737-15.2015.

Voon, V., Mole, T. B., Banca, P., Porter, L., Morris, L., Mitchell, S., \& Irvine, M. (2014). Neural correlates of sexual cue reactivity in individuals with and without compulsive sexual behaviours. PloS One, 9, e102419. https://doi.org/10.1371/journal.pone.0102419.

Wennerhold, L., Friese, M., \& Vazire, S. (2020). Why self-report measures of self-control and inhibition tasks do not substantially correlate. Collabra: Psychology, 6(1). https://doi.org/10. 1525/collabra.276.

Wetterneck, C. T., Burgess, A. J., Short, M. B., Smith, A. H., \& Cervantes, M. E. (2012). The role of sexual compulsivity, impulsivity, and experiential avoidance in internet pornography use. Psychological Record, 62, 3-18. https://doi.org/10.1007/ BF03395783.

Wierzba, M., et al. (2015). Erotic subset for the Nencki Affective Picture System (NAPS ERO): cross-sexual comparison study.
Frontiers in psychology, 6, 1336. https://doi.org/10.3389/fpsyg. 2015.01336.

Williams, R. S., Biel, A. L., Wegier, P, Lapp, L. K., Dyson, B. J., \& Spaniol, J (2016). Brain and Cognition Age differences in the Attention Network Test: Evidence from behavior and eventrelated potentials. BRAIN AND COGNITION, 102, 65-79. https://doi.org/10.1016/j.bandc.2015.12.007.

Wordecha, M., Wilk, M., Kowalewska, E., Skorko, M., Łapiński, A., \& Gola, M. (2018). "Pornographic binges" as a key characteristic of males seeking treatment for compulsive sexual behaviors: Qualitative and quantitative 10-week-long diary assessment. Journal of Behavioral Addictions, 7(2), 433-444. https://doi.org/10.1556/2006.7.2018.33.

World Health Organization (2019). ICD-11 for Mortality and Morbidity Statistics. https://icd.who.int/browse11/1-m/en\#/ http://id.who.int/icd/entity/1630268048.

Wrześniewski, K., Sosnowski, T., \& Matusik, D. (2002). Inwentarz Stanu i Cechy Lęku - STAI. Polska adaptacja STAI. Warszawa: Pracownia Testów Psychologicznych Polskiego Towarzystwa Psychologicznego.

Wytykowska, A., Białaszek, W., \& Ostaszewski, P. (2014). Psychometry-czne właściwości polskiej wersji krótkiej skali wrażliwości na kary i nagrody (SPSRQ-SF Cooper i Gomez, 2008), Studia Psychologiczne, 52(2), 28-39.

Zigmond, A. S., \& Snaith, R. P. (1983). The hospital anxiety and depression scale. Acta Psychiatrica Scandinavica, 67, 361-370. 